\title{
PADRÕES DE INVESTIMENTOS ESTATAIS EM INFRA-ESTRUTURA VIÁRIA
}

\author{
Eduardo Cesar Marques \\ Cientista Político, Pesquisador da Fapesp no Cebrap \\ Renata Mirandola Bichir \\ Bolsista da Fapesp no Cebrap
}

\begin{abstract}
Resumo: Este artigo apresenta os resultados preliminares de uma pesquisa em andamento sobre os investimentos realizados pela Prefeitura de São Paulo em infra-estrutura urbana, por meio de sua Secretaria de Vias Públicas, entre 1978 e 1998. A partir de um extenso levantamento de informações primárias acerca desse período, abrangendo todos os contratos assinados pela secretaria com empreiteiras, investigou-se a distribuição dos investimentos e suas características ao longo das administrações municipais, assim como os padrões de vitória das principais empreiteiras beneficiadas por essa política.

Palavras-chave: investimento público; infra-estrutura viária; políticas públicas.
\end{abstract}

$\mathrm{O}$ presente texto traz os primeiros resultados de uma pesquisa em andamento sobre políticas públicas e intermediação de interesses em São Paulo. Analisou-se a política de investimentos da Secretaria de Vias Públicas da Prefeitura Municipal de São Paulo, do final da década de 70 até o ano de 1998. A pesquisa toma como base um amplo levantamento de dados sobre os contratos assinados entre a secretaria e empresas privadas para a implementação de obras e serviços de engenharia. Como fonte desses dados, foram colhidas informações sobre contratações da prefeitura publicadas no Diário Oficial do Município de São Paulo, tendo sido pesquisados todos os extratos de contratos da secretaria, dia a dia, entre 1978 e 1999. A partir do material coletado, a pesquisa analisou as dimensões de espaço, poder e intermediação da política de infra-estrutura na cidade de São Paulo.

A investigação representa, até certo ponto, uma continuação de pesquisa similar sobre políticas de infra-estrutura de saneamento no Rio de Janeiro consubstanciada em Marques (2000). Considerando que se trata de duas políticas altamente espacializadas, executadas diretamente por empreiteiras de obras públicas e inseridas em comunidades de engenheiros das duas mais importantes cidades brasileiras, são inúmeros os possíveis pontos de contato. A comparação se apresenta ainda mais rica quando se considera que os órgãos estatais responsáveis pelas políticas são bastante distintos: em São Paulo tem-se a Secre- taria de Vias Públicas - SVP, pertencente à administração direta; no Rio de Janeiro, a responsável é a Companhia Estadual de Águas e Esgotos - Cedae, organizada como empresa pública. As diferenças de estrutura e estatuto jurídico têm como conseqüência, muito provavelmente, a constituição de graus diversos de autonomia decisória das agências com relação aos ambientes políticos mais amplos nos quais operam, assim como padrões de carreira e insulamento burocrático muito distintos.

A Secretaria de Vias Públicas é uma das mais importantes unidades administrativas da prefeitura paulistana. Sua relevância se expressa, em primeiro lugar, por sua histórica influência na estruturação do espaço paulistano (e ainda presente, nos dias atuais), como será discutido rapidamente na primeira seção. Além disso, as intervenções da secretaria apresentam grande importância política, chegando a consumir 13\% do orçamento municipal, em média, no período estudado. Essa proporção alcançou $27 \%$ do gasto total da Prefeitura em 1993, o que correspondeu a mais de 2,5 bilhões de reais (em valores de dezembro de 1999). Essa importância se mede também pela centralidade de suas atividades nos projetos políticos de boa parte dos prefeitos do período estudado, tanto pela realização de obras de enorme visibilidade, quanto pelo porte elevado dos valores contratados, que, como tem sido fartamente documentado pela imprensa, significam impor- 
tante moeda de negociação com financiadores de campanha e esquemas de corrupção.

A pesquisa tem indicado, na verdade, que a secretaria constitui um dos mais importantes nós do funcionamento da política paulistana, ou ao menos do grupo político que controlou a prefeitura paulistana pela maior parte do período. ${ }^{1}$ Os resultados aqui apresentados abrangem a dinâmica temporal da política e suas características em cada administração municipal, além das relações entre os investimentos e o ciclo eleitoral, as finanças municipais e os repasses orçamentários para a secretaria. ${ }^{2}$

\section{A SECRETARIA DE VIAS PÚBLICAS E O MUNICÍPIO}

A Secretaria de Vias Públicas é talvez o mais importante órgão estatal do Município de São Paulo. Apesar disso, nunca foi objeto de estudos sistemáticos como organização do Estado. As únicas pesquisas sobre a secretaria analisam-na sob o ponto de vista da obra urbanística de alguns dos seus mais importantes dirigentes, principalmente Prestes Maia e Victor da Silva Freire, ou a partir das ações da Diretoria de Obras, sua antecessora no organograma da prefeitura (Simões Jr., 1991; Leme, 1991 e 1999). Na realidade, a ausência de análises políticas sobre esse importante órgão paulistano reflete dois processos convergentes internos às comunidades acadêmicas brasileiras: a escassez de estudos empiricamente embasados de ciência política sobre as ações estatais, especialmente locais, e o pequeno conhecimento da dinâmica do poder na secretaria trazido pelos trabalhos de estudos urbanos que a têm enfocado, preocupados com outras questões e dinâmicas. A pesquisa que serve de base a este artigo pretende contribuir para preencher tal lacuna.

A secretaria tem sua origem mais remota na Diretoria de Obras da prefeitura da capital. A história desta unidade administrativa está ligada de forma indissolúvel às atividades de Victor da Silva Freire, chefe e diretor da Seção de Obras Públicas por mais de 20 anos, desde 1898, quando o conselheiro Antônio Prado tornou-se o primeiro prefeito paulistano. Em 1926, Freire deixou o setor público, mas continuou seu trabalho em urbanismo atuando como professor da Escola Politécnica (Simões Jr., 1991; Leme, 1999). O período de influência de Freire foi sucedido, na história institucional do órgão, pela presença de Francisco Prestes Maia, ingressado na Diretoria de Obras Públicas em 1918. Entre 1924 e 1926, Prestes Maia, em associação com Ulhôa Cintra, elaborou uma série de es- tudos sobre a estrutura urbana paulistana e, em 1930, publicou o seu Plano de Avenidas, que incluía uma proposta para o sistema viário que viria a influenciar as principais intervenções que estruturaram a cidade nas décadas posteriores. A diretoria existiu até 1936, quando foi transformada em Departamento de Obras e Serviços Municipais pelo Ato $\mathrm{n}^{\circ} 1.146 / 36$.

Vale dizer que a organização territorial da cidade de São Paulo ocorreu, por um lado, pela ação atomizada de empreendedores privados, e, por outro, pela realização de obras públicas, especialmente viárias e de drenagem, direcionadas tão somente a solucionar, no curto prazo, os problemas viários e de circulação rodoviária, apesar da existência de propostas mais abrangentes. A realização direta de intervenções viárias, portanto, representou a forma predominante de organização territorial, destacando importantes figuras de técnico-políticos ${ }^{3}$ realizadores como Silva Freire e Prestes Maia. Esse processo colocou o Departamento de Obras e posteriormente a secretaria - no centro das atividades estruturadoras do espaço paulistano.

No caso de Prestes Maia, mais destacado personagem da história do setor de obras públicas paulista, a influência prolongou-se por muitos anos. Embora tenha se envolvido com o lado perdedor da Revolução de 1930 e tenha se afastado das atividades públicas por um breve período, voltou ao centro da política e da gestão territorial paulistana em 1938, quando assumiu a cadeira de prefeito, por indicação do interventor Adhemar de Barros. Prestes Maia permaneceu como prefeito de Barros até 1941 e foi novamente indicado pelo novo interventor, Fernando da Silva Costa. Em 1945 Maia deixou o Departamento de Obras, que, ao final do mesmo ano, foi transformado em Secretaria de Obras e Serviços pelo Decreto-Lei n ${ }^{\circ} 333 / 45$.

A estrutura do novo órgão passou a incorporar, a partir de 1947, com o Decreto-Lei n ${ }^{\circ} 431 / 47$, os departamentos de obras públicas, serviços municipais, cadastro municipal, ${ }^{4}$ manutenção de prédios públicos e serviço funerário, além das comissões orientadoras do "Plano da Cidade" e de "Estética".

Durante a década de 50, Maia atuou por meio de seu escritório de projetos, além de se lançar a cargos eletivos pela UDN, sendo seguidamente derrotado em 1950 e 1954 para o governo do Estado. Em 1957, Jânio Quadros, primeiro prefeito eleito desde o retorno dos pleitos diretos para a prefeitura (instituído pela Lei $\mathrm{n}^{\circ} 1.720 / 52$ ), apoiou Maia para a prefeitura da capital, mas este foi novamente derrotado, dessa vez por Adhemar de Barros. Em 1961, com o apoio do governador Carvalho Pinto e do presi- 
dente recentemente eleito (e que ainda não havia renunciado) Jânio Quadros, Prestes Maia elegeu-se para a prefeitura, onde permaneceu até $1965 .^{5}$

Em 1966, o prefeito seguinte a Prestes Maia - José Vicente Faria Lima - criou as administrações regionais por meio da Lei ${ }^{\circ} 6.882 / 66$. Essas instâncias tornaram-se de fundamental importância para o funcionamento da administração pública e para a dinâmica do processo político paulistano até os dias de hoje. Naquele mesmo momento, a secretaria foi dividida em duas: de Serviços Municipais e de Obras. Em abril de 1975, no início da administração de Olavo Setúbal, as duas secretarias foram transformadas respectivamente em Secretaria de Serviços e Obras (SSO) e em Secretaria de Vias Públicas (SVP). A estrutura interna da nova Secretaria de Vias Públicas tomou, nesse momento, a feição que a caracteriza até os dias de hoje, com dois departamentos - Controle do Uso de Vias Públicas (Convias) e Iluminação Pública (Ilume) -, além de duas superintendências - Obras e Projetos. A Superintendência de Obras foi dividida internamente em: Obras 1 - Pluviais; Obras 2 - Obras de arte especiais, o que inclui pontes, viadutos e grandes estruturas; e Obras 3 Pavimentação. A de Projetos foi estruturada em quatro divisões: Proj 1 - Pavimentação; Proj 2 - Estruturas; Proj 3 - Vias; e Proj 4 - Águas pluviais. Em 1987 foi operada a última transformação institucional importante na secretaria, com a criação, pelo Decreto $\mathrm{n}^{\circ} 23.440 / 87$, do Grupo Executivo do Programa de Canalização de Córregos e Implantação de Vias de Fundo de Vale (Geprocav), que passou a ser um importante implementador da política, assim como uma destacada fonte de poder institucional.

Uma outra organização estatal fundamental na definição dos destinos da política urbana em São Paulo não está subordinada formalmente à SVP. Trata-se da Empresa Municipal de Urbanização (Emurb), criada na administração Figueiredo Ferraz, no início dos anos 70, com a finalidade de gerenciar as obras e os serviços de engenharia implementados pela Prefeitura de São Paulo. Na prática da administração, entretanto, a empresa constituiu um importante braço operacional da política urbana de grandes projetos e intervenções, recebendo vultosos repasses da secretaria, contratando empresas privadas para a execução de obras e acompanhando a sua execução. A Emurb tem sido usada como implementadora de grandes obras pela sua maior agilidade administrativa, por se tratar de uma empresa pública, em relação às unidades da administração direta da prefeitura, além de apresentar menor transparência, pois não necessita de aprovação de seu orçamento anual ou balanço pela Câmara Municipal, entre outras vantagens. A empresa está formalmente vinculada ao gabinete do secretário de vias públicas, embora tenha respondido, na prática, diretamente aos prefeitos durante grande parte do período estudado. Os únicos momentos de subordinação da empresa à secretaria dizem respeito às épocas de acúmulo, pelo secretário, do cargo de presidente da Emurb, o que aconteceu entre 1993 e 1998, com Reynaldo de Barros, secretário e Paulo Maluf e Celso Pitta, prefeitos.

\section{O Orçamento Municipal}

Como órgão da administração direta sem receitas próprias, a Secretaria de Vias Públicas depende do orçamento municipal para realizar seus investimentos. Assim, antes de se analisarem detalhadamente os investimentos da SVP, deve-se observar a dinâmica do orçamento municipal. Nesta seção, será descrita a sua dinâmica temporal geral para discutir a influência sobre os investimentos da SVP mais adiante.

O Gráfico 1 apresenta os orçamentos municipais e os valores relativos à SVP, além dos investimentos da secretaria. As duas primeiras informações se referem aos valores executados e não aos orçados, ${ }^{6}$ enquanto a terceira é produto da pesquisa primária realizada nos Diários Oficiais do município e será analisada na próxima seção. Como se verifica no gráfico, o orçamento global da prefeitura se mantém em um patamar relativamente constante entre 1978 e 1987 - em torno de 6 bilhões de reais, a números de dezembro de 1999. A partir de 1987 observase uma significativa variação, com duas quedas abruptas (entre 1989 e 1990 e entre 1993 e 1994), duas recuperações (entre 1990 e 1992 e entre 1994 e 1996) e uma queda lenta a partir de 1996.

Os valores gastos na SVP também apresentam um comportamento relativamente constante de 1978 a 1987, entre 550 e 750 milhões anuais, e uma significativa variação a partir de então, com picos em 1988, 1993, 1995 e 1996. De uma forma geral, os períodos de elevação e queda dos repasses para a secretaria coincidem com os picos e as reduções da receita municipal. A proporção do valor repassado para a SVP também varia significativamente, tendo uma média de 0,12 do orçamento municipal: Reynaldo - 0,14; Curiati - 0,17; Covas - 0,09; Jânio 0,18; Erundina - 0,09; Maluf-0,18 e Pitta-0,05. Generalizando, as administrações de prefeitos de partidos de 


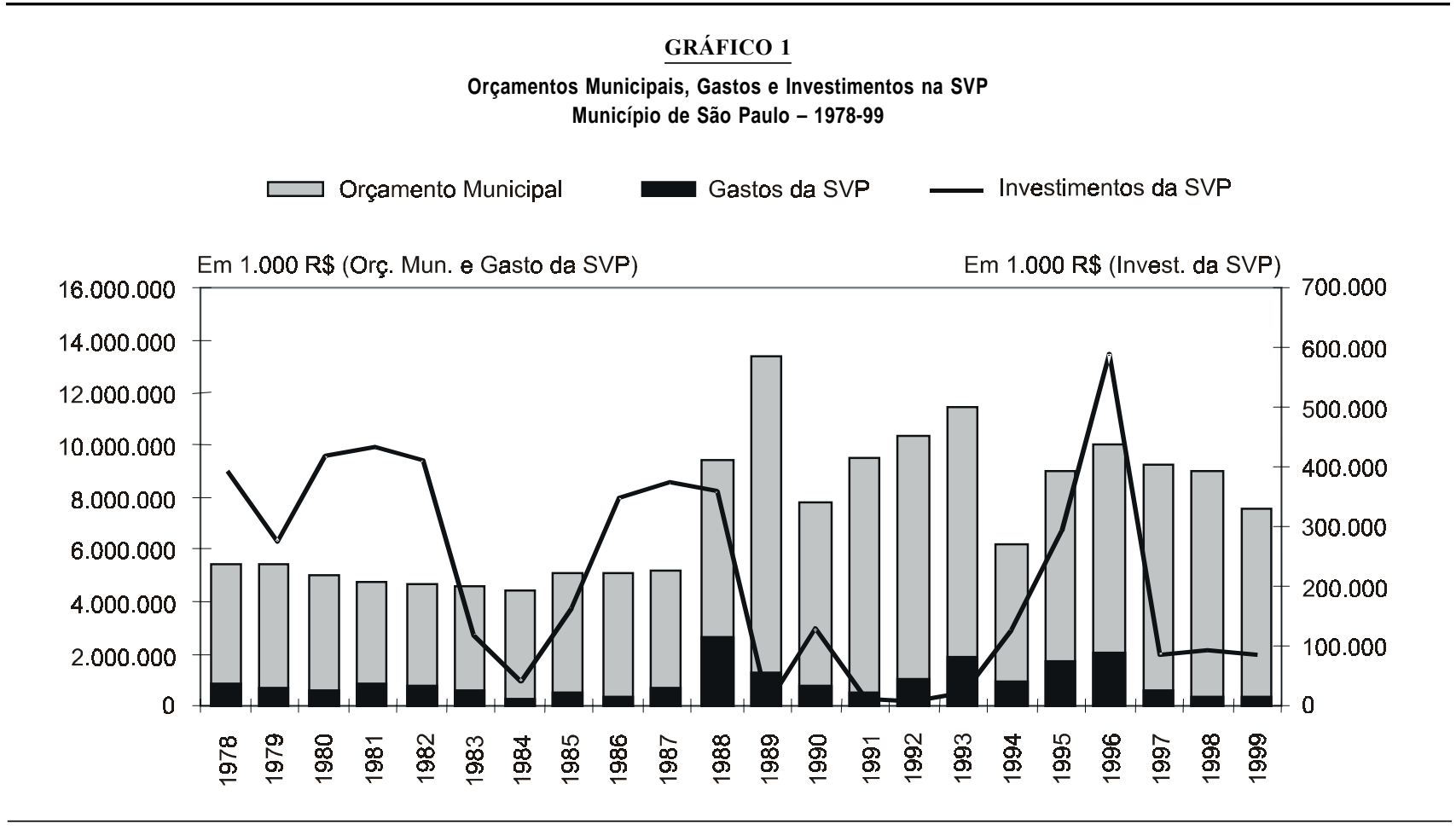

Fonte: Diários Oficiais do Municipio.

Nota: Valores em reais de dez./99.

direita - Maluf, Jânio, Curiati e Reynaldo de Barros apresentam um patamar superior de gastos aos das administrações Covas e Erundina. Como veremos, esses repasses influenciam bastante o conjunto de investimentos da secretaria. $^{?}$

\section{A Política de Investimentos}

O conjunto de investimentos analisado aqui inclui informações relativas a contratos, aditamentos de valor, retificações e aprovações de preços extracontratuais. No período, foram assinados 4.939 documentos, sendo 3.350 contratos e 1.558 aditamentos. Esses contratos foram vencidos por 355 empreiteiras, somando um valor global contratado de aproximadamente 8,2 bilhões de reais.

A primeira dimensão importante a observar diz respeito ao papel da Emurb. O conjunto de extratos de contrato indica valores extremamente elevados de repasses para a Emurb, que a partir do momento da contratação gerenciaria as obras, incluindo, com destaque, a contratação de empreiteiras e projetistas. Os valores dos repasses são extremamente elevados, alcançando em seu conjunto $\mathrm{R} \$ 3.454 .181 .015$ em números de dezembro de 1999, ou cerca de $42 \%$ do conjunto de investimentos. Os repasses são bastante concentrados no tempo, alcançando patama- res superiores a um milhão de reais em 1980 e 1981 (801 e 135 milhões), 1987 (945 milhões), 1990 (111 milhões), 1992 (1 milhão) e no intervalo de 1995 a 1999 (com 265, 991, 163, 23 e 17 milhões, respectivamente). Os repasses dizem respeito a grande parte das obras de porte muito elevado realizadas no período. Infelizmente, não houve acesso a informações que permitissem, no momento, caracterizar o conteúdo das intervenções contratadas a partir desses recursos, assim como determinar quais empresas as executaram. Por essa razão, dos investimentos da secretaria analisados, foram excluídos os repasses para a Emurb, concentrando-se na discussão e análise dos 58\% restantes dos investimentos.

O perfil dos investimentos da secretaria, excetuados os repasses para a Emurb, segue a trajetória apresentada no Gráfico 1. Os investimentos totalizam cerca de 4,8 bilhões de reais, em valores de dezembro de 1999, distribuídos por 4.924 documentos, vencidos por 355 empresas diferentes. O valor médio do documento é de cerca de 972 mil reais, embora estejam presentes contratos de 120 reais a até mais de 110 milhões de reais. A concentração dos contratos em determinadas empresas também é muito elevada, como será observado mais adiante.

Nota-se que o ciclo de investimentos segue um perfil de alternâncias, tendo valores mais altos de 1978 a 1982 
e de 1986 a 1988 (entre 200 e 400 milhões de reais), e em 1995 e 1996 (entre 300 e 600 milhões de reais). Ao contrário do que afirma uma parte significativa das literaturas de estudos urbanos e de ciência política, não existe uma associação entre o perfil de investimentos e o ciclo eleitoral. A hipótese de associação entre essas duas dimensões parte do suposto da predominância do imperativo, em regimes democráticos, da tentativa de reeleição dos governantes ou, quando essa não estiver prevista institucionalmente, da tentativa de influenciar o processo de escolha do seu sucessor, mantendo força política sobre a administração. Conseqüentemente, haveria uma coincidência (ou pelo menos forte relação) entre os ciclos eleitorais e de investimento, especialmente das políticas com grande visibilidade e impacto eleitoral (Ames, 1995a e b; Fizson, 1990). Esse mecanismo teria predominância sobre outras lógicas, por exemplo institucionais, históricas, da própria política pública e mesmo do processo político mais amplo, não deixando praticamente nenhum espaço para a escolha dos decisores públicos.

A política aqui analisada constitui um caso particularmente importante para testar tal hipótese, já que apresenta grande visibilidade e apelo eleitoral e, no caso específico de São Paulo, carrega uma importante carga simbólica ligada historicamente à "cidade que não pode parar". Confirmando estudos como o de Marques (2000), que mostraram a relativa independência entre as políticas locais, os ciclos eleitorais e as políticas nacionais, o perfil de investimentos sugere a importância central dos processos políticos locais e das escolhas políticas realizadas no interior do governo municipal, em flagrante desacordo com o que afirma a literatura.

No caso da SVP, não há relação estatística entre o perfil anual de investimentos, ou a proporção de gastos na SVP sobre o total do orçamento, e a ocorrência de eleições em um dado ano, nem mesmo se forem discriminados os anos de eleições municipais dos de pleitos não-municipais. ${ }^{8}$ Por outro lado, quando se analisa o perfil de investimentos anuais contra a ocupação da administração municipal por partidos de direita e de não-direita, ${ }^{9}$ obtêm-se resultados significativos. ${ }^{10} \mathrm{O}$ mesmo ocorre com a proporção dos repasses para a SVP e com o volume geral do orçamento municipal naquele ano. Nos dois primeiros casos, as relações são positivas, mas, no terceiro, é negativa, isto é: os investimentos da SVP tendem a crescer quando o prefeito é de direita, aumentando a proporção da SVP no orçamento, mas tendem ser menores nos anos de maior gasto global da prefeitura, o que é bastante contra-intuitivo.
Esses resultados são consistentes, tanto considerandose o efeito de cada fenômeno de maneira independente, quanto levando em conta todos ao mesmo tempo. Um modelo com os investimentos da SVP como variável dependente explicou cerca de $66 \%$ do comportamento estatístico dos investimentos da SPV pelas variáveis independentes - governos de direita/não-direita, proporção do gasto da SVP no orçamento e o volume do orçamento municipal. ${ }^{11}$ Dois dos fenômenos tomados como independentes apresentam, na verdade, uma razoável correlação entre si: a proporção da SVP no orçamento é correlacionada com o fato de o partido do prefeito ser de direita $(0,42$ de correlação). Entretanto, se analisarmos a relação dos investimentos com cada uma das variáveis separadamente, controlando pela outra, as correlações continuam altas. ${ }^{12}$

Assim, pode-se afirmar com razoável segurança que o nível anual de investimento da SVP é função, principalmente, do nível da receita total da prefeitura, da proporção repassada para a SVP e do fato de o partido do prefeito ser de direita. Embora em administrações de direita a proporção para a SVP tenda a ser mais alta do que quando o partido do prefeito não é de direita, ambos os fenômenos explicam os investimentos da secretaria, sendo cada qual responsável por uma parcela diferente da sua variação.

Passando da análise quantitativa para a política, podemos dizer que o nível geral dos investimentos da secretaria mais importante da prefeitura paulistana não depende do ciclo eleitoral, nem local nem de outros níveis de governo. Ele é principalmente função do volume geral de recursos na prefeitura e de duas variáveis políticas. Cada fenômeno deve ser observado separadamente.

Primeiro será analisada a relação contra-intuitiva entre o volume de investimentos e o orçamento municipal. Encontra-se uma correlação negativa, o que indica que, quanto maiores os volumes de recursos disponíveis para o conjunto da prefeitura, menores são os investimentos da SVP em obras e serviços. Em primeiro lugar, vale destacar que o sentido dessa relação mostra que explicações para os investimentos baseadas na disponibilidade de recursos não encontram nenhum fundamento empírico. Em segundo, sugere que não se trata de uma relação causal, mas de uma associação que expressa, na verdade, a relação entre o restante dos gastos municipais e o volume total do orçamento. A secretaria apresentaria grande importância no conjunto dos gastos, tanto porque durante uma parte significativa do período estudado os prefeitos consideraram estrategicamente as suas políticas, quanto por- 
que a importância de sua burocracia conseguiu imprimir um caráter inercial a seus gastos. Assim, a secretaria realizaria gastos segundo uma lógica que combina elementos políticos e burocráticos e conhece poucas restrições, ao contrário do restante da prefeitura, que conseguiria gastar mais quando os volumes de recursos fossem mais elevados. ${ }^{13}$ Segundo essa hipótese, os únicos elementos limitadores do volume de investimentos da secretaria seriam as escolhas políticas dos dirigentes e as dinâmicas internas ao processo de decisão, analisadas a seguir.

São duas as variáveis políticas encontradas: a inclinação político-ideológica do prefeito e a proporção do orçamento que este e seus secretários, consultados seus apoios no ambiente político mais amplo, repassam para a secretaria. Ambas as variáveis indicam escolhas ou se relacionam com elas. A primeira é o eleitorado, que, ao votar em candidatos de direita ou esquerda, pode prever o conjunto de políticas que eles implementarão, uma vez no poder. ${ }^{14}$ Restaria comprovar se os padrões de votação seguem preferências de políticas compatíveis com as políticas implementadas. Apesar de a intuição afirmar que sim, analisar essa dinâmica foge ao escopo deste trabalho. ${ }^{15} \mathrm{De}$ qualquer forma, está comprovada a presença de alta previsibilidade dos eleitores sobre o conteúdo das políticas a partir de posicionamentos políticos mais amplos na arena eleitoral, contrariamente a uma parte significativa da literatura e ao senso comum predominante na sociedade e na imprensa. A segunda relação encontrada demonstra a importância dos processos políticos ocorridos no interior do executivo (e apenas parcialmente previsíveis a partir de posicionamentos ideológicos mais amplos), indicando a importância de estudos empiricamente embasados dos processos decisórios ocorridos no interior do Estado que levam à alocação dos recursos públicos. Por hora não se pode fazer mais que levantar a questão, mas a continuidade da presente pesquisa enfocará de maneira central tal dimensão. Pela importância desses processos na definição do volume geral de investimentos, serão tomadas como unidade de análise, na próxima seção, as administrações municipais, embora se retorne às informações por ano, quando relevante. Como se verá, a clivagem direita/nãodireita não explica apenas o volume geral investido, mas inúmeros indicadores relacionados de maneira direta à implementação da política.

\section{AS ADMINISTRAÇÕES E OS INVESTIMENTOS}

Na Tabela 1 pode-se observar as principais características dos investimentos por administração municipal ordenados no tempo. Como se vê, os dados confirmam a impressão do senso comum com relação à ênfase dos governos em obras públicas: as administrações de maiores investimentos médios por mês de administração (que desconta eventuais diferenças de duração nos mandatos) são os governos Reynaldo de Barros, Setúbal, Jânio Quadros, Maluf e Salim Curiati (de curta duração, razão pela qual o total de investimentos não é tão elevado em termos relativos quanto o valor médio mensal). ${ }^{16}$ Os governos Erundina, Covas e Pitta apresentam os menores volumes de investimento, tanto absolutos, quanto relativos, em um patamar de um sétimo a um terço da média mensal. Como se verá a seguir, há uma substancial diferença entre os três governos de mais baixos valores: o cruzamento com as demais informações indica que os números inferiores de Covas e Erundina dizem res-

TABELA 1

Valores Totais e Médios Gastos, segundo Administração (Licitado e Aditado)

Município de São Paulo - 1978-99

\begin{tabular}{lcrrrr}
\hline Administração & Partidos & Total Gasto (1) & Valor Gasto/Mês (1) & $\begin{array}{c}\text { Valor Médio } \\
\text { do Documento (1) }\end{array}$ & $\begin{array}{c}\text { Número } \\
\text { de Documentos (2) }\end{array}$ \\
\hline Total & & $\mathbf{4 . 7 8 8 . 4 4 9 . 9 4 0 , 5 8}$ & $\mathbf{1 7 . 3 4 9 , 4 5 6 , 3 1}$ & $\mathbf{9 7 2 . 4 7 1 , 5 6}$ & $\mathbf{4 . 9 2 4}$ \\
Setúbal & ARENA & $616.791 .614,61$ & $32.462 .716,56$ & $1.352 .613,19$ & 456 \\
Reynaldo & ARENA & $1.176 .242 .286,63$ & $34.595 .361,37$ & $1.227 .810,32$ & 958 \\
Curiati & PDS & $223.549 .677,54$ & $18.629 .139,80$ & $1.039 .765,94$ & 215 \\
Covas & PMDB & $239.722 .839,34$ & $7.732 .994,82$ & $228.525,11$ & 1.049 \\
Jânio & PTB & $1.086 .356 .125,97$ & $22.632 .419,29$ & $1.159 .398,21$ & 937 \\
Erundina & PT & $153.277 .278,67$ & $3.193 .276,64$ & $363.216,30$ & 422 \\
Maluf & PPB & $1.058 .354 .808,97$ & $22.049 .058,52$ & $1.383 .470,34$ & 765 \\
Pitta & PPB/PTN & $234.155 .308,84$ & $6.504 .314,13$ & $1.919 .305,81$ & 122 \\
\hline
\end{tabular}

Fonte: Diários Oficiais do Município.

(1) Valores em reais de dez./99.

(2) Inclui contratos, aditamentos e retificações. 
peito a prioridades de governo, enquanto os de Pitta se devem à grave situação financeira da prefeitura, que impediu o prefeito do PPB (depois PTN) de manter os volumes elevados de investimento do governo de seu padrinho político, imediatamente anterior.

Outra informação importante diz respeito aos valores médios por documento. Nesse particular, a administração Covas ${ }^{17}$ se aproxima da de Erundina com os mais baixos valores, enquanto as administrações Pitta, Maluf, Olavo Setúbal, Reynaldo de Barros, Jânio Quadros e Salim Curiati apresentam valores em patamares muito mais elevados (de cinco a treze vezes o patamar das administrações do PMDB e do PT). Vale destacar que os valores médios das administrações Maluf, mais de duas vezes a média geral, e Pitta apresentam um valor médio de contratações bastante elevado.

A Tabela 2 complementa as informações anteriores, apresentando os índices por administração relativos a aditamentos de valor. Os maiores volumes de recursos em aditamentos estão nas administrações Maluf, Jânio Quadros, Reynaldo de Barros e Pitta. Setúbal apresenta um patamar intermediário, e Covas, Curiati e Erundina têm os menores valores totais, sendo ainda muito mais baixos na administração do PT. No tocante à relação aditamentos/investimentos, que desconta o efeito dos volumes de gastos por governo, têm-se em ordem decrescente, os governos Pitta, Maluf, Jânio Quadros e Reynaldo de Barros. Com as relações mais baixas vêm Olavo Setúbal, Covas e Erundina. Vale destacar que a relação aditado/licitado no governo Pitta $(0,5)$ indica não apenas a presença de grande quantidade de aditamentos, mas especifica o seu governo como um gestor (com muitos aditamentos) de contratos firmados na administração anterior do PPB, também caracterizada por uma alta proporção de aditamentos. ${ }^{18}$

As relações aditamento/documento refletem grandes quantidades relativas de aditamentos nos governos Pitta e Erundina e relações mais baixas nos governos Curiati e Covas. Os valores médios, por outro lado, permitem caracterizar os governos Maluf, Reynaldo, Jânio, Pitta e Setúbal como de grandes volumes de aditamentos de valores altos, e as administrações Covas e Erundina como de pequenos volumes dispersos em muitos aditamentos de baixo valor. Vale destacar novamente o elevadíssimo valor médio do governo Pitta, confirmando sua "especialização" na gestão de contratos celebrados na administração anterior.

A legislação de licitações limita os aditamentos a 25\% do valor contratado. A existência de valores superiores a essa proporção, portanto, representa uma decisão política do administrador público, seja ele indicado ou de carreira, que preferiu correr os riscos de possíveis sanções administrativas e jurídicas, embutindo novos serviços no contrato com a empreiteira atual, em vez de realizar uma nova licitação. Ao contrário do que seria de considerar, uma parcela significativa do valor aditado pelas administrações envolve aditamentos em valores superiores ao limites legais - do total aditado no período, $78 \%$ envolveu aditamentos superando o limite legal por contrato. ${ }^{19}$ A participação desses aditamentos, entretanto, varia muito entre as administrações, de $92 \%, 78 \%, 72 \%, 67 \%$ e $64 \%$ nos governos Maluf, Setúbal, Jânio, Reynaldo de Barros e Pitta, respectivamente, até $6 \%$ no governo Curiati e $16 \%$ no governo Erundina. A administração Covas apresenta uma participação intermediária desses aditamentos (31\%).

TABELA 2

Valores Totais e Médios Aditados, segundo Administração

Município de São Paulo - 1978-99

\begin{tabular}{lccccrrr}
\hline Administração & $\begin{array}{c}\text { Número } \\
\text { de Aditamentos }\end{array}$ & Total Aditado (1) & Aditado/Gasto & $\begin{array}{c}\text { Aditamentos/ } \\
\text { Documentos }\end{array}$ & Valor Aditado/Mês (1) & $\begin{array}{c}\text { Valor Aditado } \\
\text { Médio (1) }\end{array}$ \\
\hline Total & $\mathbf{1 . 5 5 8}$ & $\mathbf{7 2 4 . 4 5 4 . 5 0 5 , 4 8}$ & $\mathbf{0 , 1 5}$ & $\mathbf{0 , 3 2}$ & $\mathbf{2 . 6 2 4 . 8 3 5 , 1 6}$ & $\mathbf{4 6 4 . 9 9 0 , 0 5}$ \\
Setúbal & 108 & $54.948 .892,89$ & 0,09 & 0,24 & $2.892 .046,99$ & $508.786,05$ \\
Reynaldo & 338 & $147.658 .915,08$ & 0,13 & 0,35 & $4.342 .909,27$ & $436.860,70$ \\
Curiati & 45 & $17.945 .595,29$ & 0,08 & 0,21 & $1.495 .466,27$ & $398.791,01$ \\
Covas & 207 & $18.591 .122,87$ & 0,08 & 0,20 & $599.713,64$ & $89.812,19$ \\
Jânio & 312 & $148.730 .317,88$ & 0,14 & 0,33 & $3.098 .548,29$ & $476.699,74$ \\
Erundina & 197 & $6.399 .902,65$ & 0,04 & 0,47 & $133.331,31$ & $32.486,82$ \\
Maluf & 272 & $213.009 .019,32$ & 0,20 & 0,36 & $4.437 .687,90$ & $783.121,39$ \\
Pitta & 79 & $117.170 .739,50$ & 0,50 & 0,65 & $3.254 .742,76$ & $1.483 .173,92$ \\
\hline
\end{tabular}

Fonte: Diários Oficiais do Municipio.

(1) Valores em reais de dez./99. 
Os governos de maiores valores médios mensais de aditamentos superiores a $26 \%$ do valor dos contratos originais são as administrações Maluf, Reynaldo de Barros, Olavo Setúbal, Jânio Quadros e Pitta, com 4,1, 2,9, 2,3, 2,3 e 2,1 milhões de reais por mês, respectivamente. As três administrações restantes apresentam valores médios mensais praticamente iguais a zero: Covas, 185 mil reais; Curiati, 89,3 mil, e Erundina, 21,7 mil reais por mês. Essas informações indicam que os governos de inclinação político-partidária de direita tendem a aditar os contratos sistematicamente em valores superiores ao limite da lei, chegando a valores superiores, em média, a 4 milhões de reais e à quase totalidade do valor aditado no governo Maluf. Até onde é possível observar, essa prática não é coibida pelo poder judiciário ou pelo Tribunal de Contas, provavelmente pelos fortes vínculos entre estas organizações e o mesmo grupo que controlou a administração municipal durante a maior parte do período. ${ }^{20}$

Por fim, vale a pena considerar a distribuição dos valores contratados pelos tipos de certames licitatórios. A legislação que rege as contratações do poder público especifica tipos diferentes de certames licitatórios (cada qual com graus de exigência específica), dependendo do valor a ser contratado e do tipo de obra ou serviço a ser realizado. No caso da SVP, a distribuição dos tipos de licitação predominantes em cada administração segue os valores médios dos contratos, sendo maior a presença relativa de certames característicos de valores mais elevados - as concorrências públicas - nas administrações de maiores valores médios - Maluf, Reynaldo, Setúbal e Jânio. Entretanto, vale destacar os valores médios das dispensas de licitação por administração, tipo de certame em que o poder público escolhe a empresa a contratar, inexistindo qualquer competição. A comparação dos valores médios das dispensas confirma a distribuição das demais informações observada até o momento, com as administrações Maluf e Pitta apresentando médias de dispensas de licitação superiores a 2,5 milhões de reais, seguidas da administração Jânio Quadros, com cerca de 800 mil reais, em valores de dezembro de 1999. As demais administrações apresentam aditamentos médios em patamar inferior a 500 mil reais. A maioria das dispensas foi realizada sob a alegação de emergência.

Sumarizando, podemos dizer que as informações permitem caracterizar, de uma forma geral, os governos Maluf, Reynaldo, Jânio e Setúbal como de grandes volumes de investimentos concentrados em contratos de grande porte, que tenderam a ser aditados de maneira intensa, com valores elevados de aditamentos individuais, na sua maioria excedendo os limites legais e acompanhados de dispensas de licitação de altíssimas somas. Os governos Curiati e Pitta apresentam características próximas àqueles quatro governos, mas com algumas particularidades que se originam do caráter efêmero do primeiro e da intensa crise financeira vivida pelo segundo, advinda em grande parte do perfil de gastos da administração anterior. No outro extremo temos os governos Covas e Erundina, ambos com grandes volumes de obras pequenas e médias pouco aditadas.

\section{Concentração de Vitórias}

No total, 355 empresas venceram contratos, o que significa um valor médio por empresa de cerca de $13,5 \mathrm{mi}-$ lhões de reais. A concentração de vitórias em um número pequeno de empresas, entretanto, é muito elevada. A mais importante vencedora abocanhou $6,5 \%$ do valor contratado, as dez maiores ficaram com $34,6 \%$ e as 50 mais destacadas absorveram $80,5 \%$ do total contratado. Essa concentração nas principais empresas é um pouco menor que a encontrada por Marques (2000) para a política da Cedae, na qual a principal empresa ganhou $8,5 \%$ do total contratado, as dez primeiras somaram $46,6 \%$ e as 50 empresas mais bem colocadas ficaram com cerca de $86,7 \%$ do total. Entretanto, o conjunto da política carioca apresentou um menor número de empresas vencedoras (212), e, portanto, a observação apenas do número de empresas não permite analisar completamente o fenômeno. Quando se desconta esse efeito, comparando as proporções vencidas por parcelas iguais do universo de empresas, a concentração paulistana é levemente superior: os 5\% maiores vencedores ganharam 49\% em São Paulo e 47\% no Rio de Janeiro, os primeiros $10 \%$ venceram pouco mais de $70 \%$ no primeiro caso e $69 \%$ no segundo. No caso de São Paulo e do Rio de Janeiro, a primeira metade de empresas mais bem colocadas venceu, respectivamente, $98,8 \%$ e $96 \%$.

A dinâmica geral da concentração, entretanto, esconde a dinâmica temporal (e por governos) da concentração. De que forma variou a concentração ao longo do tempo? Esse fenômeno é observável no Gráfico 2, que mostra a proporção do valor total anual recebido por cada grupo de vencedores $(5 \%, 10 \%$ e $35 \%$ maiores, assim como os $50 \%$ menores vencedores em cada ano). Como se pode ver, há uma nítida tendência de aumento da fatia dos $5 \%$ maiores vencedores (e uma redução dos $85 \%$ menores) entre 1978 e 1983 . Os anos de 1984 e 1985 representam 
uma redução dessa tendência, inclusive com uma elevação da proporção ganha pelos $50 \%$ menores, mas tal tendência volta a ser dominante entre 1986 e 1989. Entre 1989 e 1991, a proporção dos menores vencedores torna a crescer, tanto pela fatia de contratos dos $50 \%$ menores como dos próximos $45 \%$, em detrimento dos $5 \%$ das mais importantes empresas. A partir de 1992, as vitórias se concentram mais uma vez, para alcançar em 1994 um dos seus pontos extremos, quando os $5 \%$ de empresas do topo vencem mais de $75 \%$ do valor licitado, e os $50 \%$ menores alcançam a sua pior proporção. O ano de 1995 representa um momento de redução da concentração, embora ela volte a aumentar nos três anos seguintes, para se reduzir no último ano da série. De uma forma geral, podemos notar uma tendência ao crescimento da concentração entre 1978 e 1993, com a exceção de dois períodos, nos quais o governo municipal esteve nas mãos de partidos de não-direita. Entre 1994 e 1998, a tendência geral é de redução da concentração nas $5 \%$ maiores empresas, assim como da parcela ganha pelas $50 \%$ menores, indicando uma concentração nas empresa médias, especialmente na segunda maior faixa de $10 \%$.

Mas as informações do Gráfico 2 são influenciadas pelos diferentes volumes anuais de investimento. De maneira a descontar tal efeito, o Gráfico 3 detalha a informação tentando compreender o padrão temporal geral de concentração. Nesse gráfico, a área mais escura indica os valores vencidos pelos $15 \%$ maiores vencedores em cada ano, e a área mais clara, entre a primeira e a curva do total investido, representa os volumes de recursos anuais vencidos pelos $85 \%$ menores vencedores. Fica evidenciada a presença, também no caso da SVP, de um fenômeno observado por Marques (2000) para o caso da Cedae: a fatia ganha pelas empresas menos importantes, além de muito pequena, só aumenta em termos relativos nos momentos em que os recursos gerais investidos crescem, indicando a existência de uma parcela "reservada" dos recursos anuais para os maiores vencedores.

Uma outra forma de descrever a concentração diz respeito à quantidade de empresas efetivas presentes em cada administração. Essa medida se origina da utilização da fórmula desenvolvida por Laakso e Taagepera para o cálculo do número de partidos efetivos, muito utilizada para a descrição sintética de sistemas partidários, na distribuição dos valores dos contratos. ${ }^{21} \mathrm{O}$ número efetivo considera qual seria o total de entidades existentes se a dispersão entre elas fosse igualmente distribuída. Os números por administração são os seguintes: Setúbal - 34,2; Reynaldo - 16,5; Curiati - 14,1; Covas - 50,2; Jânio 30,2; Erundina - 24,9; Maluf - 22,9; Pitta - 14,6.

O número geral de empresas efetivas do período é de 49,7 , bastante superior ao total dos diversos governos e

\section{GRÁFICO 2}

Proporção de Valor Investido, por Grupo de Empresas Município de São Paulo - 1978-98

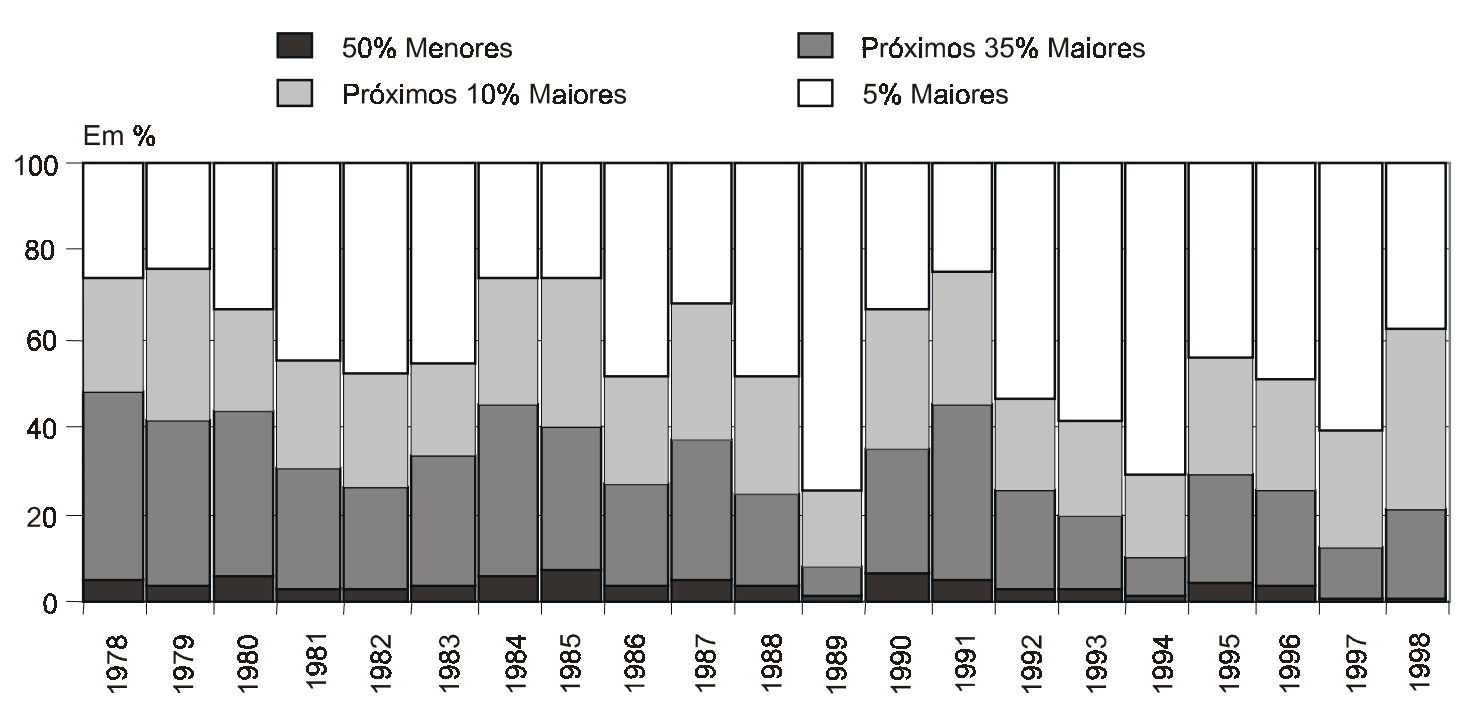

Fonte: Diários Oficiais do Municipio. 


\section{GRÁFICO 3}

Investimentos e Valores Ganhos pelos Maiores Vencedores

Município de São Paulo - 1978-98

Vencidos pelas 15\% Maiores $\quad \square$ Vencidos pelas restantes

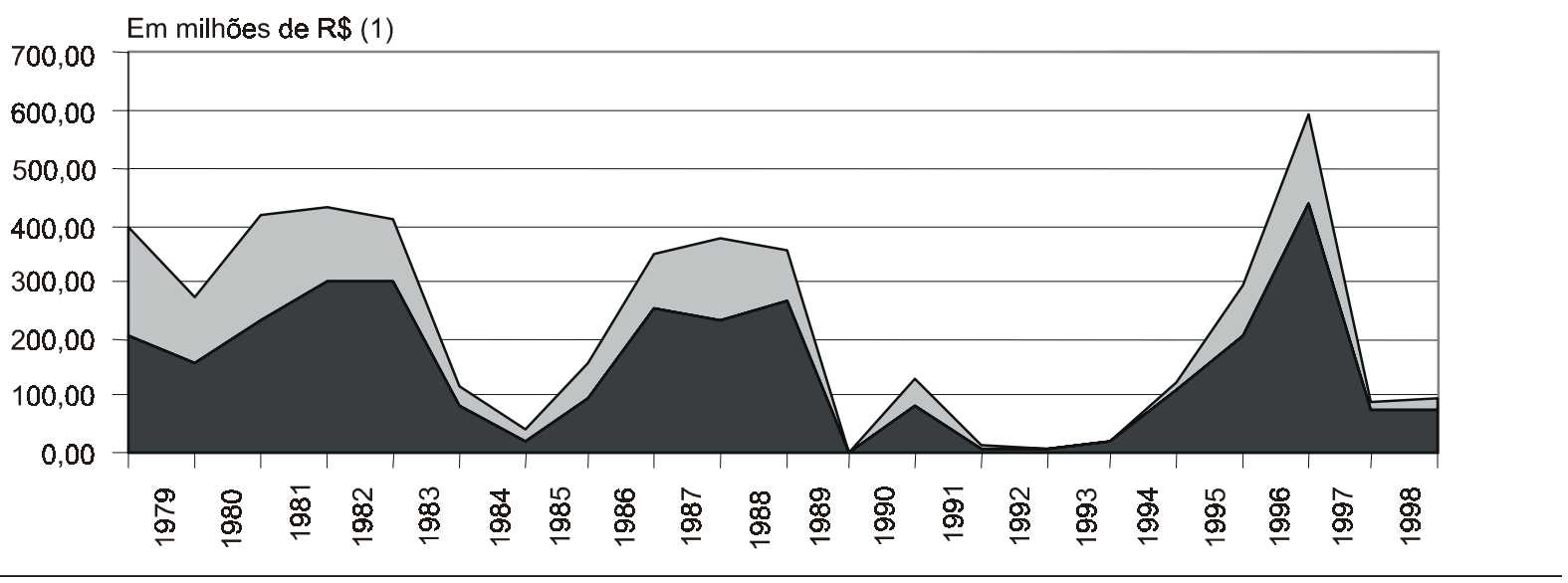

Fonte: Diários Oficiais do Municipio.

(1) Valores em reais de dez./99.

do número de empresas efetivas encontrado por Marques (2000) para a política de saneamento no Rio de Janeiro 33,1. Como já se viu que o padrão paulistano é levemente mais concentrado que o carioca, pode-se concluir que o primeiro apresenta uma maior fatia do total licitado concentrado nas mãos de empresas do meio da distribuição, com uma maior presença de empresas médias.

O governo Covas totaliza o maior número de empresas efetivas de todo o período; as administrações Setúbal, Jânio, Erundina e Maluf apresentam números médios, e as gestões Curiati e Pitta têm os menores valores. Vale registrar que o fato de o número de empresas para todo o período ser tão elevado, quando comparado com os números de empresas de cada administração indica que cada governo, mais ou menos concentrado, apresentou empresas diferentes no topo de suas contratações, o que fez com que a lista geral de vencedores fosse caracterizada por um total significativo de empresas com valores altos.

Também podemos utilizar o número de partidos efetivos (Nicolau, 1997) como artifício para comparar o capital dos principais vencedores da política, calculando o capital médio desses vencedores e tomando como parâmetro de corte para cada administração o número de empresas efetivas. Os capitais médios são: Setúbal - cerca de 63,4 milhões de reais; Reynaldo - 56,3 milhões; Curiati - 37,6 milhões; Covas - 43,1 milhões; Jânio 45,1 milhões; Erundina - 43,7 milhões; Maluf - 113,3 milhões; Pitta - 83,7 milhões. Os capitais das empresas efetivas dos governos Maluf e Pitta surgem como muito mais elevados que os dos demais governos, acrescentando à caracterização anterior - de uma administração envolvida com grandes obras, altamente aditadas, extremamente concentradas em poucas empresas contratadas - a informação de que se trata de empresas de grande porte. Em um segundo patamar se situam as Administrações Olavo Setúbal e Reynaldo de Barros, ficando as demais gestões em perfil mais baixo, em torno de 40 milhões de reais.

Por fim, vale observar o comportamento da concentração de vitórias por empresas diferentes ao longo do tempo. O Gráfico 4 apresenta uma comparação dos casos da Cedae e da SVP utilizando o índice de concentração de contratos desenvolvido por Marques (2000). Esse índice divide o número de licitações em um dado ano pelo número de empresas diferentes vencedoras naquele ano, apontando para a maior ou menor concentração dos contratos assinados nas mãos de um grupo mais ou menos restrito de empresas a cada ano. Como é possível perceber, a tendência geral do período nos dois casos foi de redução da concentração, embora incluam-se dois momentos visivelmente distintos. O primeiro, entre 1978 e 1986, apresenta altos e baixos, apesar de existir uma leve tendência decrescente. A partir de 1987, o índice cai vertiginosamente para um patamar muito inferior, conquanto cresça levemente entre 1993 e 1996. 


\section{GRÁFICO 4}

Comparação dos Índices de Concentração de Vitórias em Licitações

Município de São Paulo e Região Metropolitana do Rio de Janeiro - 1978-98

Secretaria de Vias Públicas - MSP

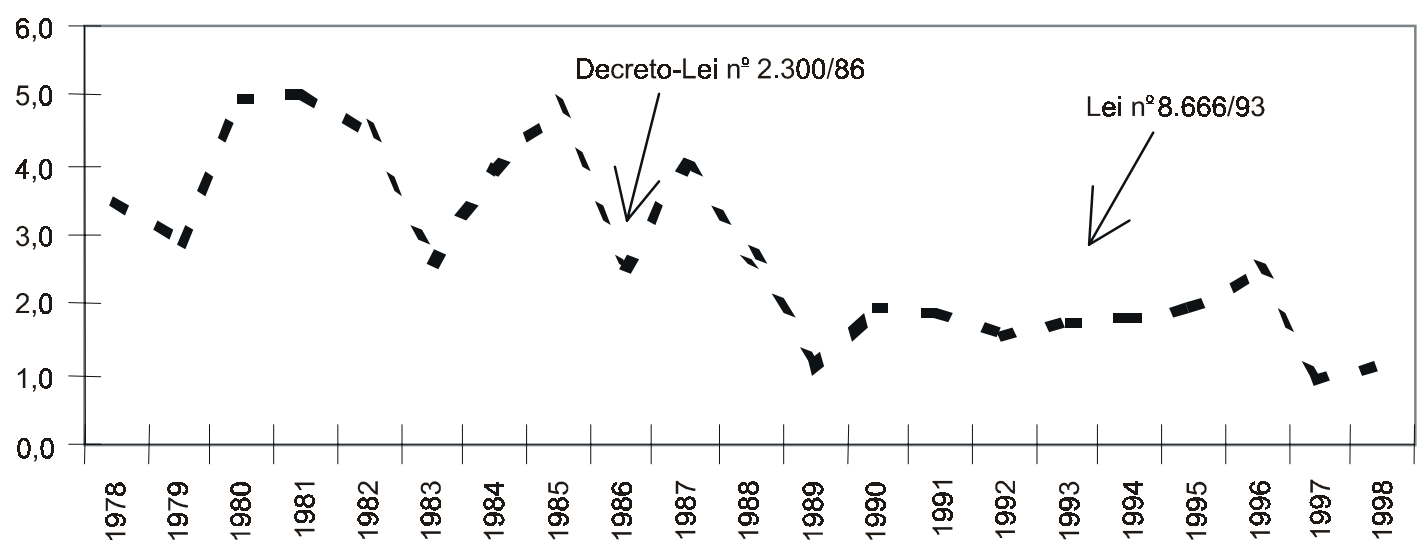

Companhia Estadual de Águas e Esgotos - RMRJ

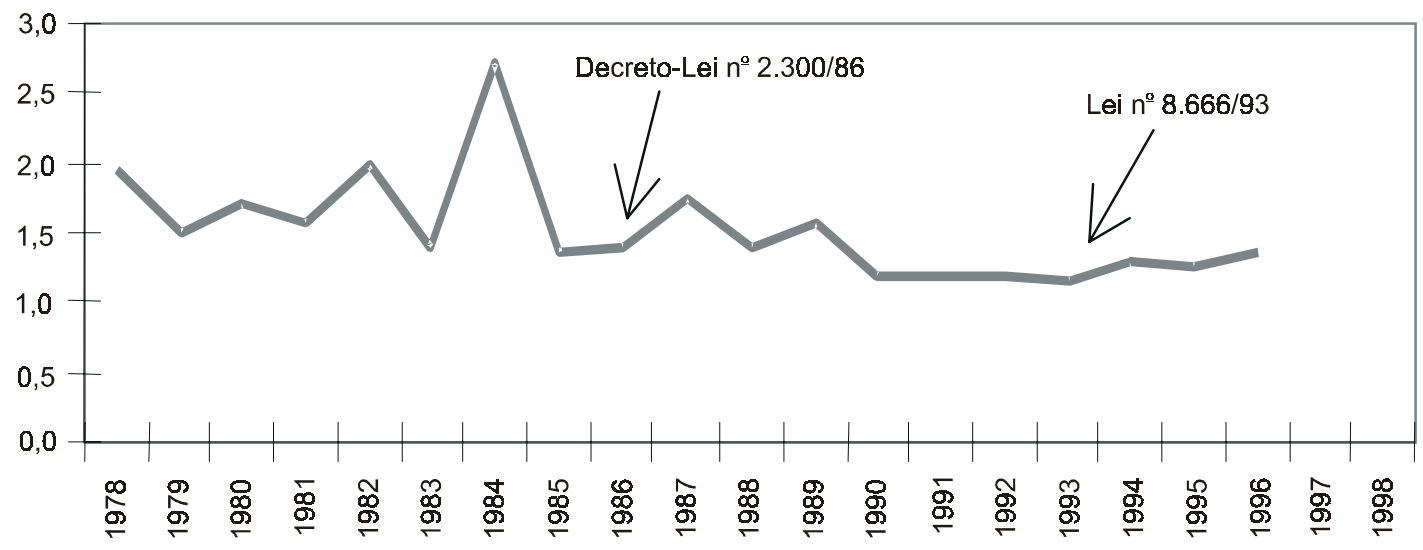

Fonte: Diários Oficiais do Municipio de São Paulo; Marques (2000).

É notável a semelhança dos dois perfis, embora haja significativa diferença entre os valores absolutos dos dois casos. O índice do caso de São Paulo se coloca em um patamar mais alto e apresenta maior queda absoluta (para facilitar a visualização, foram criados dois eixos diferentes para as duas séries). ${ }^{22}$ Essas semelhanças - em duas políticas distintas implementadas por burocracias também distintas em dois espaços urbanos muito diferenciados - confirmam a hipótese institucional de explicação levantada sobre o caso carioca. Naquele estudo, as grandes mudanças do perfil foram explicadas pela influência de dois arcabouços legais implantados nacionalmente em 1986 e em 1993. A primeira lei, o Decreto-Lei $n^{\circ} 2.300 / 86$, que constituiu o primeiro marco legal exclusivamente dedicado a licitações e contratações do poder público, democratizando as vitórias em licitações e, conseqüentemente, reduzindo a concentração de vitórias. A segunda, a Lei $\mathrm{n}^{\circ} 8.666 / 93$, aumentou muito as exigências requeridas das empresas e, segundo representantes do setor de obras públicas no Congresso afirmaram naquele mesmo momento, produziria uma elitização do mercado. Aparentemente esse efeito se fez sentir nos dois casos, e as mudanças de patamar geral nas concentrações dos contratos se devem às alterações nacionais das regras da competição em licitações. A queda verificada no caso paulista em 1997 e 1998 não pode ser comparada com o caso da Cedae, já que o período daquele estudo terminava em 1996. 


\section{CONCLUSÃO}

Como se pôde ver a partir dos resultados preliminares, o volume geral de investimentos variou bastante ao longo do tempo. Os investimentos totais parecem estar relacionados positivamente com a proporção do orçamento municipal que é repassado para a Secretaria de Vias Públicas e com o fato de o partido do prefeito ser ou não de direita, assim como negativamente correlacionado com o volume geral do orçamento municipal. Os principais elementos para a explicação do perfil estão, portanto, em escolhas políticas do eleitorado (elegendo ou não prefeitos de direita), em dinâmicas internas ao processo decisório (que levam a uma determinada proporção do gasto municipal na secretaria) e no volume geral do orçamento municipal. Não há dúvidas quanto ao funcionamento do primeiro elemento político, mas o segundo e o terceiro serão objetos de estudo detalhado no decorrer do restante desta investigação, quando houver maior aproximação dos processos de decisão e das dinâmicas no interior da burocracia.

Considerando que o perfil político-ideológico do prefeito é um dos condicionantes do volume de recursos investido em obras viárias, de drenagem e pavimentação, as informações foram agregadas segundo as administrações municipais. Os dados caminharam na mesma direção do perfil geral de investimentos: prefeitos de direita tenderam a produzir muitas obras de grande porte, a aditar mais os seus contratos, inclusive acima dos limites legais, e contratar por dispensa de licitação em valores muito elevados. Além disso, boa parte de suas licitações foram, de maneira significativa, vencidas por empresas de capital mais elevado.

Existem obviamente diferenças entre os prefeitos de direita, mas essas características, em geral, são comungadas por todos. Merece destaque, pela intensidade da presença desses conteúdos, a administração Maluf, seguida de perto da gestão de Celso Pitta. Os governos de Reynaldo de Barros, Jânio Quadros e Olavo Setúbal têm características praticamente idênticas e próximas às dos anteriores, enquanto a administração Curiati é a que apresenta menores semelhanças no interior do grupo (como já foi dito, trata-se de um governo atípico, de curtíssima duração apenas 12 meses). Do outro lado do espectro, encontramos os dois prefeitos de não-direita do período - Covas e Erundina - que tenderam a construir muitas obras de pequeno e médio valor, pouco aditadas e contratadas com empresas de capital mais modesto. Nas suas característi- cas gerais, portanto, pouca diferença foi encontrada entre esses dois governos. A continuidade dessa pesquisa tentará a qualificar a possível existência de diversidades na distribuição espacial dos investimentos, em seus aspectos redistributivos e no desenrolar dos processos de decisão.

A concentração das vitórias mostrou um padrão muito fechado de vencedores, mais restrito que o encontrado no Rio de Janeiro. Entre 1978 e 1993, a concentração nas maiores empresas vencedoras foi sempre muito grande, exceto pelos dois momentos em que a prefeitura foi ocupada por prefeitos que não eram de direita. A partir de 1994, a concentração dos 5\% maiores vencedores caiu, mas a fatia dos 50\% menos vencedores a acompanhou, apontando para uma concentração em empresas médias e grandes. Esse padrão tendeu a se atenuar apenas nos momentos de grande oferta de recursos, indicando que, somente quando os ganhos das maiores estão garantidos, as empresas da periferia do mercado de obras públicas conseguem aumentar a sua proporção de vitórias.

Por fim, a concentração geral tendeu a ser fortemente influenciada pelos arcabouços legais que regem as licitações. A análise da concentração ano a ano indicou que seus níveis costumaram ficar estáveis entre 1978 e 1986, sendo nítida a tendência de queda a partir desse ano, quando se promulga a primeira legislação federal de licitações. O efeito voltou a se fazer sentir em 1993, dessa vez aumentando a concentração, pelo caráter muito restritivo da legislação então promulgada. O impressionante paralelismo dessa desconcentração com a observada por Marques (2000) não deixa dúvidas de que o fenômeno interveniente é de natureza nacional e muito provavelmente institucional.

\section{NOTAS}

E-mail dos autores: ecmarq@uol.com.bre remibi@hotmail.com

1. A apresentação da operação do processo político, entretanto, ficará para um artigo futuro, quando as características mais gerais dos investimentos da SVP já tenham sido tratadas, objeto específico do presente trabalho.

2. Sempre que for analiticamente relevante, serão comparados os resultados obtidos com os encontrados por Marques (2000) para o caso carioca.

3. Conforme conceito elaborado por Schneider (1991).

4. O cadastro seria importante por incluir a unidade administrativa responsável por avaliações e pela taxa de melhora. A cobrança dessa contribuição, entretanto, nunca chegou a ser implementada.

5. Alguns técnicos importantes da comunidade dos engenheiros paulistas, durante a década de 80 , foram formados por Maia em sua última passagem pelo setor público, como é o caso de José Celestino Bourroul, presidente da Cohab e secretário de habitação no final dos anos 1970 e no início da década de 80 .

6. No caso de São Paulo, o fato de os orçamentos públicos não serem mandatórios adquire contornos dramáticos. Uma legislação aprovada no início da administra- 
ção Maluf aumentou a proporção do orçamento passível de remanejamento sem autorização legislativa de $2 \%$ para $15 \%$. As administrações Maluf e Pitta usaram essa lei municipal para enviar para a Câmara e aprovar orçamentos com elevados gastos em áreas sociais e remanejar, na execução, uma proporção significativa do previsto para políticas intensivas em obras e contratos, em especial as implementadas pela Secretaria de Vias Públicas. No orçamento de 2000, por exemplo, cerca de $22 \%$ do total orçado foi remanejado na direção da SVP, apenas nos seis primeiros meses ( $O$ Estado de S.Paulo, 28/08/2000). Por essa razão, são usadas aqui apenas informações relativas às proporções e aos valores executados.

Para dar idéia da importância administrativa desse procedimento, basta lembrar que, no momento atual e diante da derrota eleitoral no pleito de 1999, a maioria conservadora na Câmara Municipal vem ameaçando retornar o remanejamento sem autorização para $1 \%$ para o ano de 2001 , de forma a atar as mãos da prefeita eleita Marta Suplicy.

7. Vale ressaltar que a comparação entre as duas informações é realizada apenas no que diz respeito a suas distribuições ao longo dos anos. Essa advertência é importante pois, considerando que se trata de informações atualizadas financeiramente de duas formas muito diferentes, os dois conjuntos de valores não são comparáveis entre si valor a valor, não sendo possível misturá-los ou combinálos, por exemplo, na produção de um indicador qualquer.

8. Se forem comparadas as médias de investimentos em anos com e sem eleições, não existem evidências que permitam sustentar que haja uma diferença significativa entre as médias. O mesmo acontece se for considerada a informação sobre o ciclo eleitoral escalar, construindo variáveis dummy para os anos com eleições em geral, no primeiro caso, e com eleições municipais e com outras eleições, no segundo: não há significância nem mesmo a $90 \%$ de confiabilidade.

9. Considera-se de direita a Arena, o PDS, o PTB, o PPB e o PTN, e de nãodireita o PMDB e o PT

10. Testes de médias (direita/não-direita) indicam que há diferença, a 95\% de confiança, entre os governos de direita e de não-direita nos investimentos da SVP, nos volumes aditados e nos gastos da SVP como proporção do orçamento. Em todos os casos, governos de direita apresentam valores mais altos.

11. Tomando o coeficiente de determinação R2 como indicativo da proporção da variância explicada. A regressão respectiva apresentou uma estatística $\mathrm{F}=\mathrm{a}$ 10,96, significativa a $99 \%$ e estatísticas $t$ dos coeficientes beta todas superiores a 2,4 .

12. A correlação entre investimentos e prefeitos de direita/não-direita cai de 0,51 para 0,38 ; e a entre os investimentos e a proporção de recursos do orçamento para a SVP cai de 0,56 para 0,44 , controlando alternadamente pela variável correlacionada restante. Esse resultado já era esperado, pois é por essa razão que as três variáveis sobrevivem com significância quando incluídas juntas na regressão.

13. Essa hipótese encontra paralelo no comportamento dos volumes de contratos obtidos pelas empreiteiras mais bem-sucedidas apresentado no Gráfico 3, que será analisado na última seção.

14. E, ao contrário do que afirma uma parcela significativa da literatura urbana de inspiração marxista baseada na idéia das contradições urbanas, os condicionantes estruturais das ações do Estado devem ser entendidos como constrangimentos e não como definidores do conjunto de políticas. Se considerar-se que a política importa e destacarem-se novos sujeitos urbanos como os movimentos sociais (hoje nem mais tão novos), também se tem de incorporar como sujeitos as burocracias e a classe política, o que significa aceitar que tenham interesses próprios e que não ajam (sempre, que seja) como representantes de outros. Vale destacar explicitamente esse elemento, aparentemente já ultrapassado, para ajudar a redirecionar conceitualmente uma parte significativa das análises que não explicitam os seus paradigmas inspiradores, mas se inscrevem difusamente na tradição das determinações estruturais. Só assim esse conjunto de análises retomará o seu caráter verdadeiramente crítico.

15. Seria necessário, para isso, realizar um estudo como o de Soares (2000), partindo de pesquisas eleitorais e de aprovação de políticas, o que está fora do alcance do presente trabalho.

16. Vale destacar que a administração Salim Curiati constitui quase um mandatotampão, tendo o prefeito ocupado o cargo apenas durante o período imediatamente anterior às eleições para governador de 1982, quando o então prefeito Reynaldo de Barros saiu como candidato.

17. Segundo Ostrowsky (1989), a prioridade da administração Covas na SVP se concentrou na realização de obras de pequeno porte dispersas pela cidade, o que explicaria os pequenos valores médios e o elevadíssimo número de contratos da- quele governo. Na próxima etapa da presente pesquisa serão analisados os padrões espaciais e o escopo das políticas em cada administração.

18 Vê-se aqui também um efeito da metodologia adotada, que considerou os contratos ou aditamentos no momento em que foram realizados, optando por não trazer todos os valores aditados para a data do contrato original. Acredita-se que esse procedimento dê conta de maneira mais fidedigna do processo de decisão com relação a aditar os contratos originais. A idéia de assim proceder deve em grande parte a observações dos colegas Fernando Limongi, José Antônio Cheibub e Argelina Figueiredo a dados preliminares desta pesquisa, a quem agradecemos. 19. Optou-se por utilizar como ponto de corte 0,26 e não 0,25 para descontar o efeito do arredondamento de casas decimais, assim como de atualização financeira dos contratos e aditamentos.

20. A independência política e institucional do Ministério Público, em contraste, tem levado à denúncia de uma grande quantidade de administradores públicos. No caso de São Paulo, a maior parte $(70 \%)$ das 519 denúncias apresentadas à justiça entre 1994 e 1999 tinha relação com crimes contra a administração pública (Arantes, 2000).

21. O número de empresas efetivas é igual a $1 / \mathrm{S}$ (prop2), sendo que $\mathrm{S}$ representa o somatório e prop indica a proporção do valor total contratado com cada empresa (Nicolau, 1997).

22. O coeficiente de correlação entre os dois perfis é de 0,53 , significativo a $5 \%$ de confiabilidade, sendo idênticos os momentos de queda na segunda metade da década de 80 e de elevação a partir de 1993.

\section{REFERÊNCIAS BIBLIOGRÁFICAS}

AMES, B. "Electoral rules, constituency pressures and pork barrel: bases of voting in the Brazilian Congress". The Journal of Politics, v.52, n.2, 1995a.

"Electoral strategy under open-list proportional representation". American Journal of Political Science, v.39, n.2, 1995 b.

ARANTES, R. "Ministério Público e corrupção política em São Paulo". In. SADEK, M.T. (org.). Justiça e cidadania no Brasil. São Paulo, Ed. Sumaré, 2000.

FIZSON, J. A política nacional de saneamento de 1968 a 1984: o caso do Planasa. Dissertação de Mestrado. Rio de Janeiro, Escola Nacional de Saúde Pública Fiocruz, 1990.

LEME, M.C. "A formação do pensamento urbanístico em São Paulo, no início do século XX”. Espaço e Debates, n.34, 1991.

(org.). Urbanismo no Brasil-1895/1965. São Paulo, Fupam/Nobel, 1999.

MARQUES, E. "Redes sociais e instituições na construção do Estado e da sua permeabilidade". Revista Brasileira de Ciências Sociais, v.14, n.41, 1999a.

"Estado e empreiteiras na comunidade de políticas urbanas no Rio de Janeiro". Revista Dados, v.42, n.2, 1999b.

Estado e redes sociais: Permeabilidade e coesão nas políticas urbanas no Rio de Janeiro. Rio de Janeiro, Revan/Fapesp, 2000.

NICOLAU, J. "Notas sobre os quatro índices mais utilizados em estudos eleitorais”. In: LIMA JR. (org.). O sistema partidário brasileiro. Rio de Janeiro, Ed. FGV, 1997.

OSTROWSKY, M. Urbanização e controle de enchentes - O caso de São Paulo, seus conflitos e inter-relações. Dissertação de Mestrado. São Paulo, Escola Politécnica - USP, 1989.

PREFEITURA MUNICIPAL DE SÃO PAULO. O poder em São Paulo. História da administração pública da cidade. São Paulo, Cortez/PMSP, 1992.

SCHNEIDER, B. Politics within the state. Pittsburgh, University Pittsburgh Press, 1991.

SIMÕES JR., J. "O setor de obras públicas e as origens do urbanismo moderno na cidade de São Paulo". Espaço e Debates, n.34, 1991.

SOARES, G. "Em busca da racionalidade perdida: alguns determinantes do voto no Distrito Federal". Revista Brasileira de Ciências Sociais, n.43, 2000.

ZANCHETI, S. "Formação e consolidação da Repartição de Obras Públicas de Pernambuco (1836-1844)”. Espaço e Debates, n.34, 1991. 